\title{
Ambivalence in emotion-focused therapy for depression: The maintenance of problematically dominant self-narratives
}

\author{
ANTÓNIO P. RIBEIRO ${ }^{1}$, INÊS MENDES ${ }^{2}$, WILLIAM B. STILES ${ }^{3}$, LYNNE ANGUS ${ }^{4}$, \\ INÊS SOUSA ${ }^{5}$, \& MIGUEL M. GONÇALVES ${ }^{1}$ \\ ${ }^{1}$ Psychology, University of Minho, Braga, Portugal; ${ }^{2}$ Maia University Institute - ISMAI E Center for Psychology at \\ University of Porto, Portugal; ${ }^{3}$ Psychology, Miami University, Miami, FL, USA; ${ }^{4}$ Psychology, York University, Toronto, \\ Canada $\mathcal{E}{ }^{5}$ Mathematics and Applications, University of Minho, Guimaraes, Portugal
}

(Received 19 fanuary 2013; revised 22 October 2013; accepted 20 December 2013)

\begin{abstract}
Objective: Ambivalence can be understood as a cyclical movement between an emerging narrative novelty-an Innovative Moment (IM) - and a return to a problematically dominant self-narrative. The return implies that the IM, with its potential for change is devalued right after its emergence. Our goal is to test the hypothesis that the probability of the client expressing such form of ambivalence decreases across treatment in good-outcome cases but not in poor-outcome cases. Method: Return-to-the-Problem Markers (RPMs) signaling moments of devaluation of IMs were coded in passages containing IMs in six clients with major depression treated with emotion-focused therapy: three good-outcome cases and three pooroutcome cases. Results: The percentage of IMs with RPMs decreased across therapy in good-outcome cases, whereas it remained unchanged and high in the poor-outcome cases. Conclusions: These results were consistent with the theoretical suggestion that therapeutic failure may be associated with this form of ambivalence.
\end{abstract}

Keywords: process research; experiential/existential/humanistic psychotherapy; narrative; ambivalence

We conceptualize ambivalence as a cyclical movement in which the emergence of novelties in a client's selfnarrative, called Innovative Moments (IMs; Gonçalves, Matos, \& Santos, 2009; Gonçalves, Ribeiro, Mendes, Matos, \& Santos, 2011), is followed by a return to the client's problematically dominant self-narrative (usual way of understanding the world). That is, a novelty emerges in the therapy dialogue, but the client quickly devalues its implications for change by, minimizing, trivializing or contradicting it. The present study on ambivalence in emotion-focused therapy (EFT) for depression replicated a study by Gonçalves, Ribeiro, Stiles et al. (2011) that described how ambivalence developed in Narrative Therapy (NT) with women who were victims of intimate violence. Ambivalence was assessed using Return-to-the-Problem Markers (RPMs), which signal moments of such devaluation of IMs. In this study, we identified IMs followed by
RPMs in six cases of major depression treated with EFT, three good-outcome cases and three poor-outcome cases. These cases had been previously analyzed with the Innovative Moments Coding System (IMCS; Gonçalves, Ribeiro, Mendes, et al., 2011) by Mendes et al. (2010), and we used those IMs codes as a starting point in the present study.

\section{Narrative and Multi-voiced Conceptualization of the Self: Innovative Moments as Expressions of Non-dominant Internal Voices}

We propose that people construct meaning from the ongoing flow of experiences in the form of selfnarratives (Bruner, 1986; Hermans \& HermansJansen, 1995; Gonçalves, Matos, et al., 2009; McAdams, 1993; Polkinghorne, 1988; Sarbin, 1986; White, 2007; White \& Epston, 1990) and

Correspondence concerning this article should be addressed to António P. Ribeiro, University of Minho, Psychology, Campus de Gualtar, Braga, 4710-057 Braga, Portugal. Email: antoniopereira@piattaforma-export.com 
that, simultaneously, these self-narratives work as implicit rules that constrain the meaning constructed from the experience, shaping behavioral, cognitive, emotional, and interpersonal processes. Self-narratives are conceived as the result of the continuous dialogue between the multiple internal voices, which we view as ways of being in the world grounded in traces of the person's past experiences (Honos-Webb \& Stiles, 1998; Stiles, 1999, 2011). Constellations of similar or related experiences become linked and thus assimilated to form a community of voices, which is experienced by the person as their usual sense of self.

Self-narratives become problematic when they are too rigid and consistently exclude incongruent internal voices, that is voices representing experiences that are discrepant from how individuals typically perceive themselves (Ribeiro, Bento, Salgado, Stiles, \& Gonçalves, 2011). Typically, when clients present for psychotherapy, their dominant self-narrative is problematic in that it fails to acknowledge important parts of the client's life experience.

The excluded, non-dominant voices may be avoided or warded off, but they do not disappear. Instead, when they are addressed by external life events, they may emerge and express themselves. When they do, they typically cause distress, but they also constitute an IM. Change in psychotherapy occurs as clients move from a dominant selfnarrative that excludes important internal voices to a more functional self-narrative that incorporates the previously excluded voices. We have proposed that this process occurs through the emergence, accumulation and articulation of IMs. When non-dominant voices express themselves during IMs, the current community of voices, organized according to the currently problematically dominant self-narrative, is disrupted, at least temporarily, and an opportunity for assimilating the excluded voices emerges.

\section{Ambivalence as a Reaction to Innovative Moments}

Although the emergence of IMs opens the possibility for change, allowing the novelty to be expanded in therapy, it also destabilizes a person's usual way of understanding and experiencing, thus creating unpredictability and uncontrollability, threatening clients' sense of self-stability (Ribeiro \& Gonçalves, 2010). Whether or not IMs develop into a new selfnarrative depends on the way this threat is managed: An IM can be amplified, or its meaning may be devalued by the client, thus reducing its potential to produce change. Amplification refers to the expansion of a given meaning present in an IM, creating an opportunity for development to occur, as in the following example.

Agoraphobic client: Today, I confronted my fears and went out [IM], and this made feel stronger and hopeful [IM amplification].

Conversely, devaluation refers to the minimization, depreciation or trivialization of a particular meaning present in an IM, resulting in the maintenance of the old problematic patterns, as in the following example.

Agoraphobic client: Today, I confronted my fears and went out [IM], but I'm sure tomorrow I'll feel miserable and weak again! [IM devaluation]

We have previously reported that in poor-outcome cases, as well as in initial and middle phases of good-outcome cases, clients tend to devalue IMs by bypassing, minimizing, depreciating, or trivializing their meaning, and quickly returning to the dominant self-narrative, promoting stability (Gonçalves, Ribeiro, Stiles, et al., 2011; Ribeiro et al., 2011; Santos, Gonçalves, \& Matos, 2010). For instance, in the beginning of therapy, when Jan (a good-outcome case of EFT from the York I Depression Study; Greenberg \& Watson, 1998; Honos-Webb, Surko, Stiles, \& Greenberg, 1999; Leiman \& Stiles, 2001) expressed feelings of dependency or weakness (nondominant voice) - that is, when she experienced IMs - she frequently restated the need to be strong and independent (dominant voice), thus returning to the problematic self-narrative (Figure 1). This sort of ambivalence is also illustrated by the reactions that emerge when clients hesitantly begin to face fears, saying, in effect: "I had enough of my fears and limitations. I will free myself from my fears, no matter what the implications are (IM) ... but I'm too weak for this." (Return to the problematically dominant self-narrative.)

Thus, IMs and the problematically dominant selfnarrative can act as opposite self-positions in a negative feedback loop relation. In this repetitive process, the client oscillates, first elaborating the IM, which temporarily disrupts the dominant self-narrative (briefly freeing the client from its oppression), then returning to the dominant self-narrative, reducing the discrepancy created by the innovation along with the associated anxiety.

Ambivalence may thus result in a form of stability, which may be understood as two opposing parts of the self that keep feeding into each other, dominating the self alternately, producing distress as they do so. This conceptualization is congruent with other theoretical accounts of ambivalence. Engle and collaborators (Engle \& Arkovitz, 2008; Engle \& 


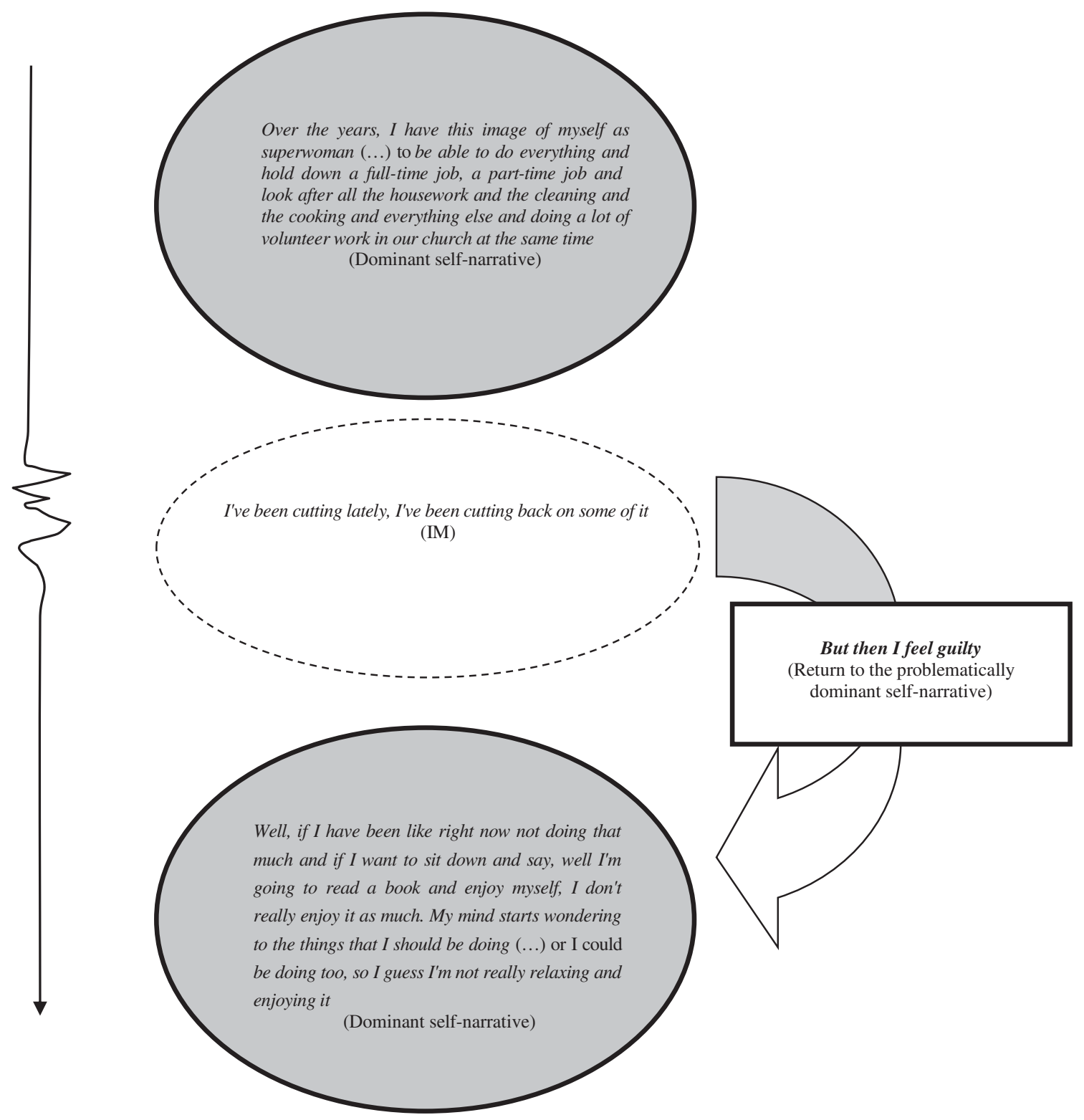

Figure 1. Avoiding self-discrepancy by returning to the problematically dominant self-narrative: The case of Jan (session 1).

Holiman, 2002) have emphasized, from a humanistic-experiential perspective, that psychological changes introduce discrepancy or inner contradiction. This discrepancy may be experienced as a threat, evoking a self-protective response in which the discrepant experience is "distorted, denied, or inadequately symbolized" (Engle \& Arkovitz, 2008, p. 391), keeping clients safe from anxiety, as they respond to changing from something familiar into something unknown. From a dialogical point of view (Valsiner, 2002; see also Hermans, 1996), the client performs a cyclical movement between a voice (IM) and a counter-voice (problematically dominant self-narrative) that interferes with further development, leading to an "impasse or a state of 'stuckness' (cf. Perls, 1969)" (Honos-Webb \& Stiles, 1998, p. 28).
Brinegar, Salvi, Stiles, \& Greenberg (2006) used the term rapid cross-fire to describe this oscillation between the overt expressions of two contradictory internal voices. As each voice triggers contradiction by the other, they seem "to fight for possession of the floor" (Brinegar et al., 2006, p. 170). EFT (Greenberg, Rice, \& Elliot, 1993) uses the term conflict splits to describe this sense of struggle between two opposite aspects of the self that pull the person in different directions. In each of these characterizations of conflicting internal self-positions, the dialogue maintains the person's status quo and, when extended over time, can be conceptualized as forms of resistance to change.

Not all cases remain stuck in ambivalence, however. In some cases, clients move from rapid cross- 
fire toward an inclusive system of meaning in which opposite internal voices respectfully listen to each other and engage in joint action (see Brinegar et al., 2006).

\section{Measurement of Ambivalence}

To measure the sort of ambivalence in which an IM emerges and is immediately followed by a return to the problematically dominant self-narrative, we have proposed a system for coding Return-to-the-Problem Markers (RPMs; Gonçalves, Ribeiro, Stiles, et al., 2011). The following example was drawn from the case of George, a poor-outcome case of EFT from the York I Depression Study (Greenberg \& Watson, 1998; Honos-Webb, Stiles, Greenberg, \& Goldman, 1998), whose depression was related to his feelings of inadequacy and inability to provide for his family. This view of himself as a failure permeated his relationships with significant others, particularly with his mother, with whom he had a distant relationship. When George experienced IMs, they were usually followed by a RPM, as in the following excerpt:

\section{Session 5}

C: I don't feel so depressed about it [referring to his low income] as I had been in the past (IM) but it's frustrating that I still have to go through the anguish of the problem as far as the money is concerned. (RPM)

In this example, George described an IM-“I don't feel so depressed about it as I had been in the past" - and then returned to the problematically dominant self-narrative by saying "but it's frustrating that I still have to go through the anguish of the problem as far as the money is concerned." This clause introduced by the word but represented opposition or negation towards what was being said and hence constitutes a RPM.

The results obtained in the study of narrative therapy with women who were victims of intimate violence ( $N=10$; Gonçalves, Ribeiro, Stiles, et al., 2011) showed that IMs were much more likely to be followed by a RPM in the poor-outcome cases than in the good-outcome cases. The good- and pooroutcome cases had similar levels of symptom severity at intake, but the poor-outcome cases showed dramatically higher percentages of RPMs in the later parts of therapy. This observation is consistent with the theoretical suggestion that ambivalence between IMs and the problematically dominant self-narrative can interfere with the therapeutic progress.

\section{Hypothesis}

In this study we extended our method for coding RPMs to another type of therapy-EFT. We hypothesized that the probability of IMs containing RPMs decreases across treatment in good-outcome cases, as the novelties are expanded and assimilated, but not in poor-outcome cases.

\section{Method}

Data, including IMs codes, were drawn from the Mendes et al. (2010) study of IMs in EFT. Relevant parts of that study's method are summarized here; please see Mendes et al. (2010) for additional details.

\section{Clients}

We studied six clients who received EFT as participants in the York I Depression Study (Greenberg \& Watson, 1998), a project designed to assess and compare EFT (then known as process-experiential therapy) with client-centered therapy for major depression (diagnosed according to the DSM-III-R; APA, 1987). The treatment in both conditions entailed 16 to 20 sessions of individual psychotherapy once a week. These six cases (three good and three poor outcome cases) were previously chosen from the 17 clients who received EFT in the York I study for intensive process analyses. Four were women and two were men (age range $=27-63$ years, $M=45.50, S D=13.78$ ). Five of the clients were married, and one was divorced.

\section{Therapists and Therapy}

EFT incorporates the client-centered relational conditions (empathy, unconditional positive regard, and genuineness; Rogers, 1957) and adds experiential and gestalt interventions to facilitate the resolution of maladaptive affective-cognitive processing. These EFT interventions included focusing (Gendlin, 1981) at a marker of an unclear felt sense, systematic evocative unfolding for problematic reactions, twochair dialogue for self-evaluative and selfinterruptive conflict splits, and empty-chair dialogue for unfinished business with a significant other (Elliott, Watson, Goldman, \& Greenberg, 2004; Greenberg et al., 1993; Greenberg \& Watson, 2006).

Five therapists (four women, one man) conducted the individual therapy for the six clients analyzed in this study (two of the poor-outcome clients, numbers 4 and 6 , were treated by the same therapist). Their levels of education varied from advanced doctoral students in clinical psychology to $\mathrm{PhD}$ 
clinical psychologists. Four therapists were Caucasian and one was Indian. All therapists received 24 weeks of training according to the York I Depression Study manual (Greenberg et al., 1993): 8 weeks of client-centered therapy training, 6 weeks of systematic evocative unfolding training, 6 weeks of twochair dialogue training, and 4 weeks of empty-chair dialogue training.

\section{Measures}

Beck Depression Inventory (BDI). The BDI is a 21-item self-report instrument assessing symptoms of depression (Beck, Steer, \& Garbin, 1988; Beck, Ward, Mendelson, Mock, \& Erbaugh, 1961). The items are rated on a 4-point Likert scale, from 0 to 3, with total scores ranging from 0 to 63 . Internal consistency in this sample was $\alpha .92$.

Innovative Moments Coding System (IMCS). The IMCS tracks IMs, that is, moments in which the problematically dominant self-narrative is challenged (Gonçalves, Ribeiro, Mendes, et al., 2011). Coders consensually distinguish facets of each client's problematically dominant self-narrative (e.g., lack of assertiveness, sense of inability) and then identify independently the moments in which these facets are challenged (e.g., moments of assertiveness, sense of empowerment). In previous studies, the IMCS has proved to be reliable; the average inter-judge percentage of agreement on overall IMs salience (the proportion of session occupied by each IM) ranged from $84 \%$ to $94 \%$ (calculated as the overlapping of the salience identified by both judges divided by the total salience identified by either judge; Gonçalves, Ribeiro, Mendes, et al., 2011).

Return-to-the-Problem Coding System (RPCS). As described in the manual for RPCS, (Gonçalves, Ribeiro, Santos, Gonçalves, \& Conde, 2009), this qualitative system analyzes the re-emergence of the problematically dominant self-narrative (through RPMs) immediately after the emergence of an IM or within the client's first speaking turn after the therapist's first intervention following the IM narration. Gonçalves, Ribeiro, Stiles et al. (2011) reported very good agreement between judges on coding RPMs, with a Cohen's $k$ of .93 .

\section{Procedure}

IM coding and reliability. Mendes et al. (2010) applied the IMCS to all session transcripts of the six selected EFT cases. Two judges participated; both were $\mathrm{PhD}$ students in psychology. One judge coded the entire sample and another judge independently coded $50 \%$ of the sessions of the sample $(n=53)$. Reliability indexes were computed on the $50 \%$ of sessions coded by both judges. The percentage of agreement on overall IMs salience was $88.7 \%$.

Two steps in this process of coding IMs are relevant to the present analysis: (1) consensual definition of the facets of the problematically dominant self-narrative by the two coders and (2) identification of each IM, defining its beginning and end.

The first step of the process of coding therapy sessions involved a careful reading of all transcripts. Coders then independently listed the clients' problems (or facets of the problematically dominant self-narrative) and met to discuss their understanding of what constituted each client's problematically dominant self-narrative. The problems were identified and consensually defined (as close as possible to the client's discourse). To make this procedure clearer, we give the following example of problematically dominant self-narrative identified in the case of Lisa, a well-known EFT client from the York I Depression Study sample ("The Case of Lisa," 2008; Gonçalves, Mendes, Ribeiro, Angus, \& Greenberg, 2010). One of Lisa's problematic self-narrative themes was "resentment and difficulty in expressing her own feelings":

L: Maybe that's why I don't tell him how I really feel inside (sniff) ... yeah, there's, or um, even though I express it, it's just kind of laughed at.

As we already stated, an IM is, by definition, an exception to this theme:

L: ...but then my feelings are my feelings and I'm entitled to them.

To allow coders to track what were identified as IMs within the client discourse, the sessions were independently coded in chronological order. When the client started to talk about any content that constituted an exception to the previously identified problematically dominant self-narrative, coders identified IM onset and offset.

RPM coding and reliability. The same two judges participated in the RPM coding procedure as participated in the IMCS coding. This coding was done 2 years after the IMCS coding had been completed. Training for RPM coding began with reading the manual for the RPCS (Gonçalves, Ribeiro, et al., 2009). Next, the two judges coded RPMs in a workbook that included transcripts of all IMs from one psychotherapy case. This step was followed by a discussion of discrepancies with a group of other RPM judges in training and/or with a skilled RPM judge. After this discussion, they coded 
a second workbook that included transcripts of all IMs from a second psychotherapy case. Their codes were then compared with the codes of expert judges. Judges were considered reliable if they achieve a Cohen's $k$ higher than .75 , which was the case.

RPMs coding comprised two sequential steps: (1) independent coding and (2) resolving disagreements through consensus. Both judges coded the entire sample (1260 IMs), analyzing IMs coded by Mendes et al. (2010) for the presence of RPMs, following the RPCS manual. The sessions were coded from the transcripts in the order they occurred. Reliability of identifying RPMs, assessed by Cohen's $k$, was .85 , based on the initial independent coding of a sample size of 1260 IMs. Throughout the coding process, the two judges met after coding each session and noted differences in their perspectives of the problems and in their RPM coding. When differences were detected, they were resolved through consensual discussion. During the collaborative meetings, the judges discussed the strengths of each other's coding and the criteria used to achieve them. Through this interactive procedure, the judges were able to integrate each other's strengths, which facilitated the coding of subsequent sessions (cf., Brinegar et al., 2006). The analysis was then based on the consensus between the two judges.

Good- and poor-outcome cases. Clients were previously classified by Greenberg and Watson (1998) as having good or poor outcome based on a Reliable Change Index (RCI; Jacobson \& Truax, 1991) analysis of the BDI (Beck et al., 1961, 1988) pre-therapy score (assessment interview) and BDI post-therapy score (last session). Based on a BDI cutoff score of 11.08 and RCI criteria, three clients were identified as "recovered" (i.e., with a good outcome) and three were classified as "unchanged" (i.e., with a poor outcome) at treatment termination. BDI scores declined dramatically from pretest to posttest for the three good-outcome cases but change little for the poor-outcome cases (see Table I).

No significant differences between the good-outcome and poor-outcome cases were found for number of sessions. The level of symptom severity on the pretreatment BDI was significantly different between the two outcome groups, with goodoutcome clients scoring significantly higher (greater severity) than poor-outcome clients. Mendes et al. (2010) reported that the global salience of IMs (proportion of session transcript involving IMs) was higher in the good-outcome group than in the pooroutcome group.

\section{Results}

Table I shows the percentage of IMs that were followed by RPMs along with the frequencies of IMs and RPMs in each of the six cases. There was a good deal of variation from case to case but no significant difference between good- $(M=21.70 ; S D$ $=2.92)$ and poor-outcome cases $(M=29.77 ; S D=$ 10.38; Mann-Whitney $U=6.00, p=.51$ ) in the percentage of IMs followed by RPMs.

To test our hypothesis that the probability of IMs containing RPMs decreases across treatment in good-outcome but not in poor-outcome cases, we modeled the probability of IMs containing RPMs using a Generalized Linear Model (GLM). The GLM analysis allowed us to construct a longitudinal regression model of the probability of RPMs as a linear function of therapy outcome (good vs. poor outcome) and time (from session 1 to 20)—explanatory variables-through the logit link function (this function allows outcomes to vary between 0 and 1) (McCullagh \& Nelder, 1989). We included a subject-specific random effect to take variability among individuals into account given that we expected that measurements (RPMs) from the same client would be correlated.

The results are presented in Figure 2, in which the $y$ axis represents the probability of RPM occurring and the $x$ axis therapy sessions over time. The estimated probability of RPMs at baseline was $35.9 \%$ for poor outcome and $48.7 \%$ for good outcome. Results indicated that these probabilities were statistically different $(p=.013)$. With respect to the estimated probability of RPMs at the last session, the pooroutcome group presented $31.4 \%$, whereas the goodoutcome group presented $4.5 \%$. Again, these probabilities were statistically different $(p<.0001)$.

Moreover, the effect of interaction between time and outcome was statistically significant $(p<.001)$. This means that the slopes of two outcomes were significantly different: the probability of RPM decreased in the good-outcome group, whereas it

Table I. Pre to post BDI scores, total of IMs, total of RPMs and percentage of IMs followed by RPMs.

\begin{tabular}{lcccc}
\hline Case & $\begin{array}{c}\text { Pre- } \\
\text { post BDI }\end{array}$ & $\begin{array}{c}\text { Total } \\
\text { IMs }\end{array}$ & $\begin{array}{c}\text { Total } \\
\text { RPMs }\end{array}$ & $\begin{array}{c}\text { \% IMs followed } \\
\text { by RPMs }\end{array}$ \\
\hline 1 & $25-3$ & 305 & 84 & 27.54 \\
2 & $30-5$ & 355 & 68 & 19.15 \\
3 & $35-4$ & 214 & 33 & 15.42 \\
4 & $15-13$ & 187 & 66 & 35.29 \\
5 & $23-22$ & 140 & 27 & 19.29 \\
6 & $24-18$ & 125 & 59 & 47.2 \\
\hline
\end{tabular}

Note. Cases 1, 2 and 3 belong to the good-outcome group and cases 4,5 and 6 constitute the poor-outcome group. 


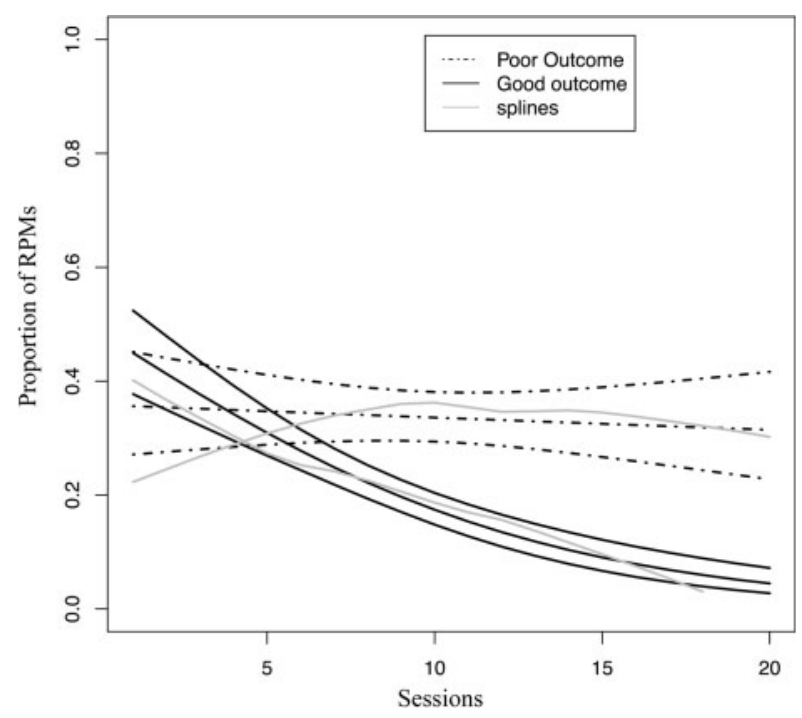

Figure 2. The evolution of RPMs in good- and poor-outcome groups.

remained unchanged in the poor-outcome group, as hypothesized.

\section{Discussion}

Our results showed that RPMs emerge in both groups, which is consistent with the theoretical suggestion that ambivalence-oscillation between novelty and problematically dominant self-narrativemight be an integral part of the change process (cf., Engle \& Holiman, 2002; Mahoney, 2003). Whereas Gonçalves, Ribeiro, et al. (2011) found that IMs were much more likely to be followed by a RPM in the poor-outcome cases than in the good-outcome cases of narrative therapy, the good- and poor-outcome cases of EFT had similar overall proportions of IMs containing RPMs. This could reflect sample variation (numbers of clients in both studies were small) or different selection criteria operating in which clients entered these studies.

Replicating the finding that good- and pooroutcome groups followed different trajectories across treatment was consistent with the theoretical suggestion that therapeutic progress involves overcoming ambivalence. The probability of RPMs decreased in the good- outcome group, whereas it remained high in the poor-outcome group (Figure 2). These results are congruent with EFT's dialectical constructivist view of the self in which the awareness and "confrontation between two opposing prior self-organizations", facilitated, for instance, by chair work (Greenberg \& Watson, 2006, p. 40), facilitates integration between discrepant parts of self and the construction and consolidation of new meanings into a new self-organization (Elliott et al., 2004; Greenberg \& Watson, 2006). That is, it is plausible that the declining pattern of RPMs in the goodoutcome cases reflected clients attaining a sense of integration between the innovative voice and the voice of the problematically dominant self-narrative. In contrast, the poor-outcome group's probability of RPMs remained high until the end, suggesting that clients did not resolve the conflicts between the two parts of the self.

\section{Limitations and Conclusion}

Characteristics of our sample, such as its small size, restriction to depression, and the requirement of willingness to participate in research, restrict generalizing results of the hypotheses tested. Also, the fact that the same therapist followed two out of three poor-outcome cases emphasizes the nonrandom selection of cases and hence uncertain representativeness of our sample. Our design does not, of course, admit any causal claims.

Nevertheless in a Bayesean sense, our observations in this study add a little confidence to the theory that (1) ambivalence might be a rather frequent process in both good- and poor-outcome cases due to the potential disruptive nature of IMs, and (2) ambivalence tends to decrease across treatment in goodoutcome cases but not in poor-outcome cases. Clinically, overcoming ambivalence reflects therapeutic progress whereas the persistence of ambivalence in later stages of therapy may reflect a lack of therapeutic progress. Further, RPMs may offer an opportunity. They may indicate readiness for change in the sense that intruding and dominant voices are responding to each other. A therapist who can listen and respond to their separate expressions may be able to facilitate a successful negotiation between them.

This study's success corroborates the applicability of our method for coding RPMs to different therapeutic models (EFT) and to different problems (depression). It helps build confidence in RPCS coding as a transtheoretical method for identifying ambivalence in psychotherapy.

We have cast ambivalence as a kind of stuck conversation in which two competing voices are pulling in different directions. As the study and other studies (e.g., Brinegar et al., 2006) have shown, however, sometimes such ambivalence can be overcome. Future work might profitably investigate therapeutic strategies for addressing and overcoming ambivalence (cf., Ribeiro et al., in press.) 


\section{Funding}

This article was supported by the Portuguese Foundation for Science and Technology (FCT) by the grant PTDC/ PSI-PCL/121525/2010 (Ambivalence and unsuccessful psychotherapy, 2011-2014) and by the Postdoctoral research grant SFRH/BPD/ $84157 / 2012$.

\section{References}

American Psychiatric Association. (1987). Diagnostic and statistical manual of mental disorders (3th ed., rev.). Washington DC: Author.

Beck, A. T., Steer, R. A., \& Garbin, M. G. (1988). Psychometric properties of the Beck Depression Inventory: Twenty-five years of evaluation. Clinical Psychology Review, 8, 77-100. doi:10.1016/ 0272-7358(88)90050-5

Beck, A. T., Ward, C. H., Mendelson, M., Mock, J., \& Erbaugh, J. (1961). An inventory for measuring depression. Archives of General Psychiatry, 4, 561-571. doi:10.1001/ archpsyc.1961.01710120031004

Brinegar, M. G., Salvi, L. M., Stiles, W. B., \& Greenberg, L. S. (2006). Building a meaning bridge: Therapeutic progress from problem formulation to understanding. Fournal of Counseling Psychology, 53, 165-180. doi:10.1037/0022-0167.53.2.165

Bruner, J. (1986). Actual minds, possible worlds. Cambridge, MA: Harvard University Press.

Elliott, R., Watson, J. C., Goldman, R., \& Greenberg, L. S. (2004). Learning emotion-focused therapy: The process-experiential approach to change. Washington DC: American Psychological Association.

Engle, D., \& Arkowitz, H. (2008). Viewing resistance as ambivalence: Integrative strategies for working with ambivalence. Fournal of Humanistic Psychology, 48, 389-412. doi:10.1177/0022167807310917

Engle, D., \& Holiman, M. (2002). A gestalt-experiential perspective on resistance. $\mathcal{F C L P / I n}$ Sessions: Psychotherapy in Practice, 58, 175-183.

Gendlin, E. T. (1981). Focusing (2nd ed.). New York: Bantam Books.

Gonçalves, M. M., Matos, M., \& Santos, A. (2009). Narrative therapy and the nature of "innovative moments" in the construction of change. Fournal of Constructivist Psychology, 22, 1-23. doi:10.1080/10720530802500748

Gonçalves, M. M., Mendes, I., Ribeiro, A. P., Angus, L., \& Greenberg, L. (2010). Innovative moments and change in emotional focused therapy: The case of Lisa. Fournal of Constructivist Psychology, 23, 267-294. doi:10.1080/107 20537.2010.489758

Gonçalves, M. M., Ribeiro, A. P., Mendes, I., Matos, M., \& Santos, A. (2011). Tracking novelties in psychotherapy process research: The Innovative Moments Coding System. Psychotherapy Research, 21, 497-509. doi:10.1080/10503307.2011.560207

Gonçalves, M. M., Ribeiro, A. P., Santos, A., Gonçalves, J., \& Conde, T. (2009). Manual for the Return to the Problem Coding System - version 2. Unpublished manuscript, University of Minho, Braga, Portugal.

Gonçalves, M. M., Ribeiro, A. P., Stiles, W. B., Conde, T., Santos, A., Matos, M., \& Martins, C. (2011). The role of mutual in-feeding in maintaining problematic self-narratives: Exploring one path to therapeutic failure. Psychotherapy Research, 21, 27-40. doi:10.1080/10503307.2010.507789

Greenberg, L. S., \& Watson, J. (1998). Experiential therapy of depression: Differential effects of client-centered relationship conditions and process interventions. Psychotherapy Research, 8, 210-224. doi:10.1080/10503309812331332317

Greenberg, L. S., \& Watson, J. C. (2006). Emotion-focused therapy for depression. Washington DC: American Psychological Association.

Greenberg, L. S., Rice, L. N., \& Elliott, R. (1993). Facilitating emotional change: The moment-by-moment process. New York: The Guilford Press.

Hermans, H. J. (1996). Opposites in a dialogical self: Constructs as characters. Fournal of Constructivist Psychology, 9, 1-26. doi:10.1080/10720539608404649

Hermans, H. J. M., \& Hermans-Jansen, E. (1995). Self-narratives: The construction of meaning in psychotherapy. New York: Guilford.

Honos-Webb, L., \& Stiles, W. B. (1998). Reformulation of assimilation analysis in terms of voices. Psychotherapy, 35, 23-33. doi: $10.1037 / \mathrm{h} 0087682$

Honos-Webb, L., Stiles, W. B., Greenberg, L. S., \& Goldman, R. (1998). Assimilation analysis of process-experiential psychotherapy: A comparison of two cases. Psychotherapy Research, 8, 264-286.

Honos-Webb, L., Surko, M.,Stiles, W. B., \& Greenberg, L. S. (1999). Assimilation of voices in psychotherapy: The case of Jan. Fournal of Counseling Psychology, 46, 448-460. doi:10.1037/ 0022-0167.46.4.448

Jacobson, N.S., \& Truax, P. (1991). Clinical significance: A statistical approach to defining meaningful change in psychotherapy research. Fournal of Consulting and Clinical Psychology, 59, 12-19. doi:10.1037/0022-006X.59.1.12

Leiman, M., \& Stiles, W. B. (2001). Dialogical sequence analysis and the zone of proximal development as conceptual enhancements to the assimilation model: The case of Jan revisited. Psychotherapy Research, 11, 311-330. doi:10.1080/713663986

Mahoney, M. J. (2003). Constructive psychotherapy: Practices, processes, and personal revolutions. New York: Guilford Press.

McAdams, D. P. (1993). The stories we live by: Personal myths and the making of the self. New York: William Morrow.

McCullagh, P., \& Nelder, J. (1989). Generalized linear model. London: Chapman \& Hall.

Mendes, I., Ribeiro, A. P., Angus, L., Greenberg, L., Sousa, I., \& Gonçalves, M. M. (2010). Narrative change in emotionfocused therapy: how is change constructed through the lens of the innovative moments coding system? Psychotherapy Research, 20, 692-701. doi:10.1080/10503307.2010.514960

Polkinghorne, D. E. (1988). Narrative knowing and the human sciences. Albany: State University of New York Press.

Ribeiro, A. P., \& Gonçalves, M. M. (2010). Innovation and stability within the dialogical self: The centrality of ambivalence. Culture \& Psychology, 16, 116-126. doi:10.1177/1354067X093 53211

Ribeiro, A. P., Bento, T., Salgado, J., Stiles, W. B., \& Gonçalves, M. M. (2011). A dynamic look at narrative change in psychotherapy: A case-study tracking innovative moments and protonarratives using state-space grids. Psychotherapy Research, 21, 34-69. doi:10.1080/10503307.2010.504241

Ribeiro, A. P., Cruz, G., Mendes, I., Stiles, W. B., \& Gonçalves, M. M. (2012). Ambivalence in client-centered therapy. Manuscript in preparation.

Ribeiro, A. P., Ribeiro E., Loura, J., Gonçalves, M. M., Stiles, W. B., Horvath, A., \& Sousa, I. (in press). Therapeutic collaboration and resistance: Describing the nature and quality of the therapeutic relationship within ambivalence events using the Therapeutic Collaboration Coding System. Psychotherapy Research.

Rogers, C. R. (1957). The necessary and sufficient conditions of psychotherapeutic personality changes. Fournal of Counselling Psychology, 21, 95-103.

Santos, A., Gonçalves, M. M., \& Matos, M. (2010). Innovative moments and poor-outcome in narrative therapy. Counselling 
and Psychotherapy Research. Advance online publication doi:10.1080/14733140903398153

Sarbin, T. R. (1986). The narrative and the root metaphor for psychology. In T. R. Sarbin (Ed.), Narrative psychology: The storied nature of human conduct (pp. 3-21). New York: Praeger. Stiles, W. B. (1999). Signs and voices in psychotherapy. Psychotherapy Research, 9, 1-21.

Stiles, W. B. (2011). Coming to terms. Psychotherapy Research, 21, 367-384. doi:10.1080/10503307.2011.582186
Valsiner, J. (2002). Forms of dialogical relations and semiotic autoregulation within the self. Theory and Psychology, 12, 251-265. doi:10.1177/0959354302012002633

White, M. (2007). Maps of narrative practice. New York: Norton. White, M., \& Epston, D. (1990). Narrative means to therapeutic ends. New York: Norton. 